\title{
Effects of the endogenous clock and sleep time on melatonin, insulin, glucose and lipid metabolism
}

\author{
L Morgan, J Arendt, D Owens ${ }^{1}$, S Folkard ${ }^{1}$, S Hampton, \\ $S$ Deacon, J English, D Ribeiro and K Taylor
}

School of Biological Sciences, University of Surrey, Guildford, Surrey GU2 5XH, UK and ${ }^{1}$ MRC Body Rhythms and Shiftwork Centre, Department of Psychology, University of Wales, Swansea SA2 8PP, UK

\begin{abstract}
This study was undertaken to determine whether the internal clock contributes to the hormone and metabolic responses following food, in an experiment designed to dissociate internal clock effects from other factors. Nine female subjects participated. They lived indoors for 31 days with normal time cues, including the natural light: darkness cycle. For 7 days they retired to bed from $0000 \mathrm{~h}$ to $0800 \mathrm{~h}$. They then underwent a 26-h 'constant routine' (CR) starting at $0800 \mathrm{~h}$, being seated awake in dim light with hourly $88 \mathrm{Kcal}$ drinks. They then lived on an imposed $27-\mathrm{h}$ day (18 $\mathrm{h}$ of wakefulness, $9 \mathrm{~h}$ allowed for sleep), for a total of 27 days. A second 26-h CR, starting at $2200 \mathrm{~h}$, was completed. During each CR salivary
\end{abstract}

melatonin and plasma glucose, triacylglycerol (TAG), non-essential fatty acids (NEFA), insulin, gastric inhibitory peptide (GIP) and glucagon-like peptide-1 (GLP-1) were measured hourly. Melatonin and body temperature data indicated no shift in the endogenous clock during the 27-h imposed schedule. Postprandial NEFA, GIP and GLP-1 showed no consistent effects. Glucose, TAG and insulin increased during the night in the first CR. There was a significant effect of both the endogenous clock and sleep for glucose and TAG, but not for insulin. These findings may be relevant to the known increased risk of cardiovascular disease amongst shift workers.

Journal of Endocrinology (1998) 157, 443-451

\section{Introduction}

Health problems of shift workers include disturbed sleep patterns and poor sleep quality, increased incidence of cardiovascular disease and gastrointestinal disorders. The causes are multifactorial; however a major factor is considered to be the maladaptation of endogenous circadian rhythms to abrupt changes in shift times (Akerstedt 1995). The endogenous clock governing the circadian system normally adapts slowly to imposed phase shifts such as are found in shift work and jet lag and many night shift workers show very little adaptation. To the extent that any physiological function depends on internal circadian timing it will show abnormal responses during the period of adaptation. There is good evidence that the use of strategies to hasten circadian adaptation to night shift results in improved sleep, alertness and performance (Czeisler et al. 1990). In contrast, there is a paucity of data concerning the time-dependent hormonal and metabolic responses to food and to what extent they are governed by the circadian clock. Glucose tolerance decreases during the day in normal individuals (Carroll \& Nestel 1973, Service et al. 1983). The persistence of a diurnal variation of glucose tolerance following a standard meal (Owens et al. 1996) or glucose itself (Van Cauter et al. 1989) in a constant routine (constant environment, continuously low levels of activity, constant caloric intake and absence of sleep) suggests that at least part of the variation is controlled by the circadian clock. Diurnal variation has also been reported in a number of gastrointestinal hormones including glucose-dependent insulinotropic peptide (GIP), gastrin and motilin but to our knowledge these have not been assessed in a constant routine.

We have recently reported that immediately after a simulated 9-h phase advance, such as might be found in rotating shift work or after Eastward time zone change, postprandial insulin and glucose responses to a standard mixed meal were significantly greater than to the same meal at the same external clock time before the phase shift (Hampton et al. 1996). The changes were suggestive of insulin resistance, a risk factor for cardiovascular disease (Reaven 1988). Furthermore, triacylglycerol (TAG) showed delayed postprandial clearance after the phase shift indicating possible lipid intolerance - another risk factor for cardiovascular disease. Thus each time a day worker starts night shift or an adapted night worker starts a day shift they are likely to show hormonal and metabolic abnormalities. In view of the importance of the associated pathology we consider that it is important to investigate the mechanisms involved in order to devise counter measures.

In order to determine to what extent the internal clock contributes to the hormonal and metabolic responses 
observed following a meal we have undertaken an experiment designed to dissociate the effects of the internal clock from other factors.

\section{Materials and Methods}

Subjects

Nine female undergraduates took part in the study. They were aged 19-20 years and of mean body mass index $20 \cdot 19 \pm 2 \cdot 98$ (range 16.42-26.30). Ethical permission for the study was obtained from the University of Wales Swansea Ethical Committee in accordance with the guidelines issued by the Royal College of Physicians 1984 and all subjects gave written informed consent. The study took place between 22 March and 21 April 1995.

\section{Experimental protocol}

The subjects entered a small hall of residence at the University of Swansea in which they were then confined for a total of 31 days. Normal time cues were present throughout the study, including clocks and watches, access to television and radio programmes and the natural light: darkness cycle through windows. For the first 7 days of the study they were required to retire to bed in darkness at $0000 \mathrm{~h}$ and were woken at $0800 \mathrm{~h}$ the following morning to establish normal circadian rhythmicity. Following this baseline period the subjects underwent a 26-h 'constant routine' (constant routine 1) starting at $0800 \mathrm{~h}$, during which they remained seated (except for visits to the toilet), awake at a desk under dim light conditions (range 0.5-42 lux). Subjects were given liquid test 'meals' of Complan (Beechams, Brentford, Middx, UK) at hourly intervals on the hour throughout the constant routine period. Each 'meal' contained $12 \mathrm{~g}$ carbohydrate, $4.2 \mathrm{~g}$ protein and $2.9 \mathrm{~g}$ fat with an energy content of $384 \mathrm{~kJ}$ (total energy intake $/ 24 \mathrm{~h}=9592 \mathrm{~kJ}$ ). The total 24-h energy and macronutrient intake was representative of a typical Western diet. At the end of the first constant routine subjects were allowed to sleep for nine hours and were then requested to live on a $27-\mathrm{h}$ day (18 h of wakefulness, $9 \mathrm{~h}$ allowed for sleep), but still in the presence of normal time cues. Thus bed times and meal times were delayed by $3 \mathrm{~h}$ each day. A total of $17 \times 27 \mathrm{~h}$ days were completed i.e. just over $19 \times 24$ h days. The study ended with a second 26-h constant routine as before but starting at $2200 \mathrm{~h}$ (constant routine 2). The schedule is shown in Fig. 1. The subjects ate a controlled vegetarian diet throughout the study except during the constant routines. The meals were chosen to be similar in terms of energy and macronutrient content. Subjects' mean daily energy intake was $9287 \pm 173 \mathrm{~kJ}$, comprising $49 \cdot 5 \pm 2 \cdot 0 \%$ carbohydrate, $38 \cdot 1 \pm 1 \cdot 6 \%$ fat and $12 \cdot 4 \pm 2 \cdot 0 \%$ protein.

\section{Sampling and recording}

Throughout the study subjects wore wrist activity monitors (Gaehwiler actigraphs, Gaehwiler Electronics,

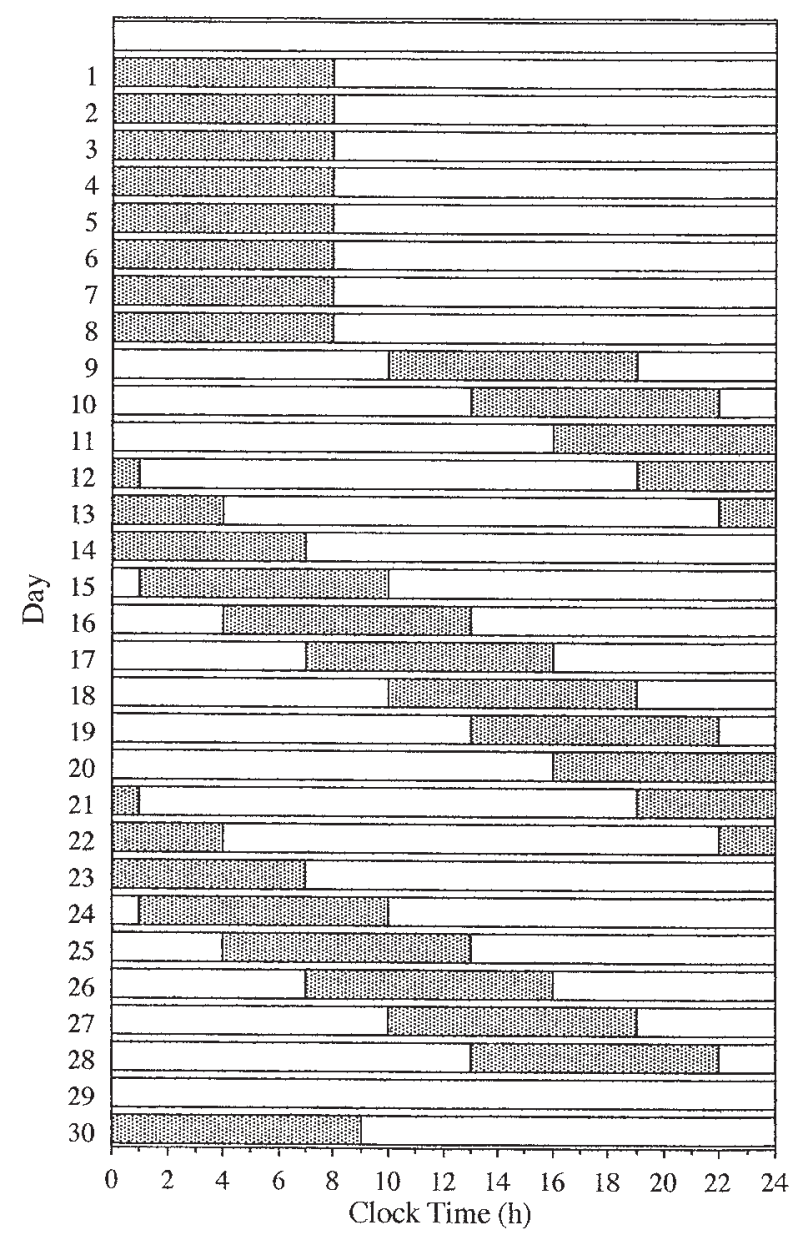

Figure 1 Experimental schedule used to force desynchrony in volunteers. Shaded areas, periods of enforced rest or sleep with lights turned off. Open areas, subjects awake.

Hombrechtikon, Switzerland) and rectal temperature was recorded continuously every 6 min (Squirrel data loggers, Eltek, Cambridge, Cambs, UK). Throughout the study tests of mood and cognition were completed at 2-h intervals whilst subjects were awake. Prior to each constant routine subjects were cannulated in an arm vein under local anaesthetic (lignocaine) and two fasting blood samples $(12 \mathrm{ml})$ were taken. Twelve millilitres blood were then withdrawn at hourly intervals $30 \mathrm{~min}$ following ingestion of each Complan drink into lithium-heparin tubes for the measurement of TAG, insulin, GIP and glucagon-like peptide-1 (GLP-1) and into fluoride oxalate tubes for glucose estimation. To prevent GLP-1 and GIP degradation, a protease inhibitor, aprotinin $(200 \mathrm{KIU} / \mathrm{ml}$ blood) was added to the tubes used to collect these samples. Plasma was separated immediately by centrifugation, aliquoted and stored at $-20{ }^{\circ} \mathrm{C}$. At the same time $5 \mathrm{ml}$ saliva was collected into a polypropylene vial, frozen and stored at $-20{ }^{\circ} \mathrm{C}$. 


\section{Biochemical analyses}

The analysis and results for activity and rectal temperature are reported elsewhere (Minors et al. 1996). Melatonin was measured in saliva by RIA (English et al. 1993), with reagents supplied by Stockgrand Ltd (University of Surrey, Guildford, Surrey, UK). The limit of detection was $1 \cdot 5 \pm 0 \cdot 2 \mathrm{pg} / \mathrm{ml}$ and the inter- and intra-assay coefficients of variation were less than $10 \%$. Plasma immunoreactive insulin, GIP and GLP-1 levels were measured using established in-house radioimmunoassays (Hampton 1983, Morgan et al. 1978, Elliott et al. 1993). The sensitivities of the immunoreactive insulin, GIP and GLP-1 assays were 19,30 and $8 \mathrm{pmol} / 1$ respectively. Their inter- and intraassay coefficients of variation were all less than $10 \%$. Plasma glucose, non-esterified fatty acids (NEFA) (Wako, Neuss, Germany) and TAG (Roche, Basle, Switzerland) were measured by standard automated enzymatic spectrophotometric methods. The interassay coefficients of variation were less than 5\% for these assays. For all analyses, samples obtained from each constant routine from each subject were measured in the same assay.

\section{Data and statistical analyses}

Data from the fasting blood samples for insulin, glucose, GIP, GLP-1, TAG and NEFA from each leg were evaluated by paired $t$-tests. Postprandial hormone data from each leg were then subjected to repeated measures analysis of variance, factor time, with a GreenhouseGeisser correction for sphericity, to determine the presence of any variations. The two fasting samples and the first postprandial sample were excluded as subjects were considered not to have reached a steady postprandial state until two hours after the start of the 'meals'.

Melatonin onset was defined as the time when the saliva concentration reached 4 times the limit of detection of the assay, provided that this was followed by two further detectable values, or the time of the value at 2 times the S.D. of the mean baseline where detectable, provided that this was followed by two further equal or greater values. There were no important differences in the timing of melatonin (see Results) indicating that no shift in the endogenous clock had occurred during the 27-h imposed schedule. This observation was also confirmed by the core temperature data (Minors et al. 1996). Thus, for each constant routine, internal 'clock' time was constant in relation to real time, whereas length of prior wakefulness and actual sleep time for any given 'real time' were different. This effectively enables a separate estimation of the effects on the variables studied of the endogenous circadian clock (C) and of the displaced sleep/wake cycle as assessed by length of prior wakefulness (W). For example, the first sample of each constant routine (at $0830 \mathrm{~h}$ and $2230 \mathrm{~h}$ real time respectively) was $0.5 \mathrm{~h}$ after wake up, the second (at 0930 and $2330 \mathrm{~h}$ real time) was
$1.5 \mathrm{~h}$ after wake up etc. Thus, using the sampling sequence as the base, $\mathrm{W}$ is constant and $\mathrm{C}$ is different. Comparison of the data from each constant routine, using sample number as the base, by repeated measures ANOVA using a Greenhouse-Geisser correction for sphericity, was used to determine whether there was a reliable C effect. Subtraction of the data from each leg at each postprandial sampling time after wake up leads to an estimate of the internal clock contribution to the variability for each subject. Having derived the internal clock component for each subject this can then be subtracted from the raw data from each leg to give the $\mathrm{W}$ component. The time-dependent changes of glucose, TAG, insulin, GIP and GLP-1 were evaluated in this way and the two components $\mathrm{C}$ and $\mathrm{W}$ were then subjected to repeated measures analysis of variance, factor time, with a Greenhouse-Geisser correction, to assess the reliability of any effects. In view of the design of the experiment it was necessary to combine adjacent values such that 2-hourly means (referenced to the mid point of the 2-h period) were used for calculation of $\mathrm{W}$ in order to normalise the time periods compared.

\section{Results}

The salivary melatonin profiles plotted as a function of clock time and of time after waking are shown in Fig. 2 for each constant routine. Inspection suggests that the overall timing of melatonin production with respect to external clock time was unchanged albeit with a small change in duration of secretion. Mean onset and offset times for leg one were $21 \mathrm{~h} 46 \mathrm{~min} \pm 45 \mathrm{~min}$ and $8 \mathrm{~h}$ $45 \mathrm{~min} \pm 53 \mathrm{~min}$, and for leg two were $21 \mathrm{~h} 35 \mathrm{~min} \pm 1 \mathrm{~h}$ $23 \mathrm{~min}$ and $8 \mathrm{~h} 56 \mathrm{~min} \pm 30 \mathrm{~min}$ respectively, indicating that no shift in the endogenous clock had occurred during the 27-h imposed schedule.

Mean fasting levels of hormones and metabolites are shown in Table 1. There were no significant differences in fasting glucose, insulin, TAG, NEFA, GIP or GLP-1 levels between the constant routines for the two fasting samples.

The plasma profiles for glucose, insulin and TAG, plotted as a function of clock time and of time after waking are shown in Figs 3, 4 and 5. Two subjects with blocked cannulae provided insufficient samples for this initial analysis. In each case, plotted as a function of time after waking, the differences between the legs appear as the contribution of the internal clock component. Plotted as a function of external clock time the differences appear as the contribution of displaced sleep (and external time cues) to the variability between the study legs. All three variables show an increase during the night around $2200 \mathrm{~h}$ to $0600 \mathrm{~h}$ on constant routine 1 , with a minor daytime peak in the case of glucose and TAG and a larger daytime peak in the case of insulin. The profiles for constant 

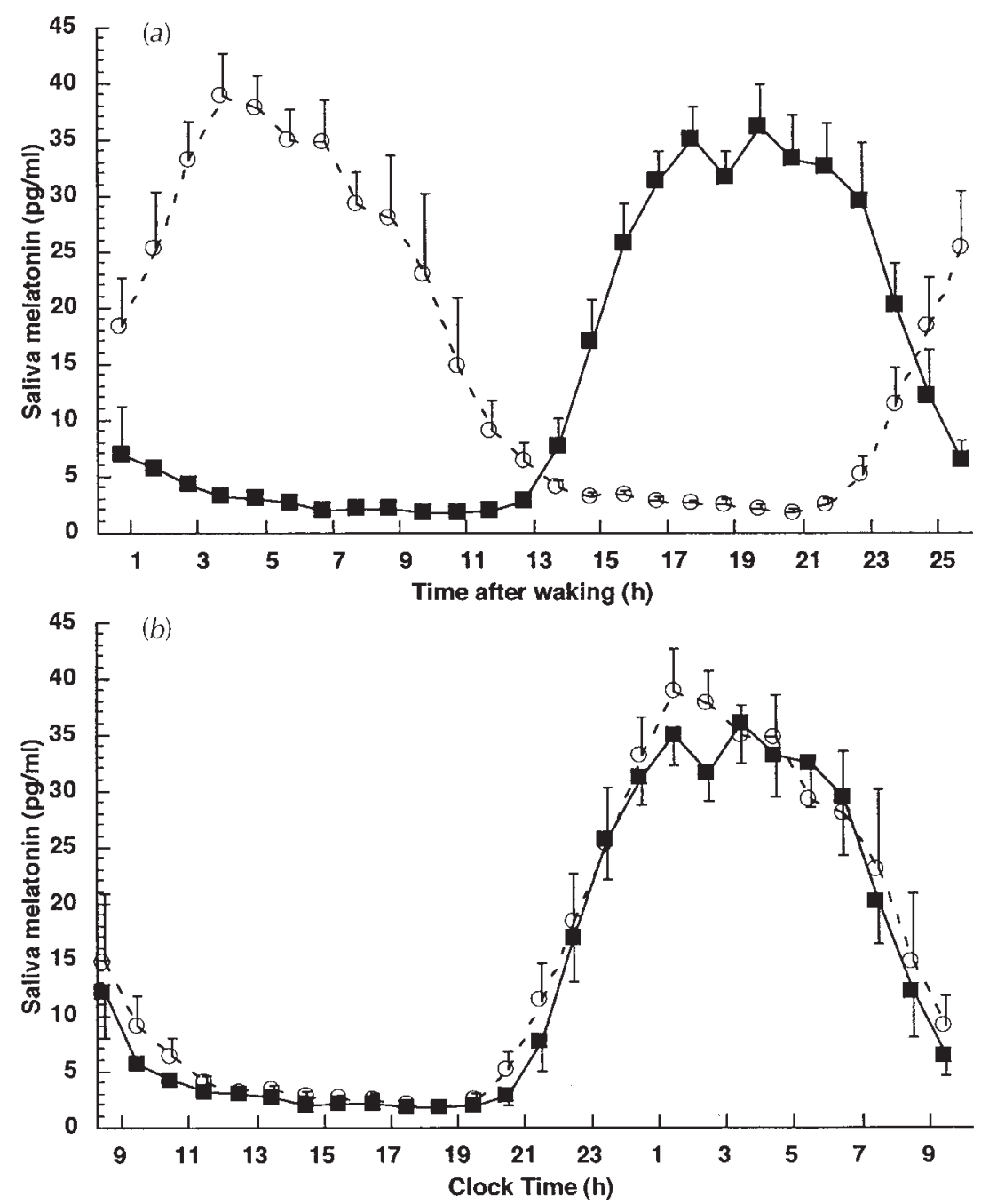

Figure 2 Salivary melatonin concentrations in healthy volunteers during the two constant routines (a) plotted as a function of time after waking and (b) postprandial samples plotted as a function of clock time. Values are means \pm S.E.M., $n=9$. $\mathbf{\square}$, first constant routine; $\bigcirc$, second constant routine.

Table 1 The effect of clock time on fasting hormone and metabolite concentrations. Plasma concentrations in subjects at the beginning of each constant routine day are shown. Values are means \pm S.E.M., $n=7$

\begin{tabular}{|c|c|c|c|c|c|c|}
\hline & $\begin{array}{l}\text { Glucose } \\
(\mathrm{mmol} / \mathrm{l})\end{array}$ & $\begin{array}{l}\text { TAG } \\
(\mathrm{mmol} / \mathrm{l})\end{array}$ & $\begin{array}{l}\text { NEFA } \\
(\mathrm{mmol} / \mathrm{l})\end{array}$ & $\begin{array}{l}\text { Insulin } \\
(\mathrm{pmol} / \mathrm{l})\end{array}$ & $\begin{array}{l}\text { GIP } \\
(\mathrm{pmol} / \mathrm{l})\end{array}$ & $\begin{array}{l}\text { GLP-1 } \\
(\mathrm{pmol} / \mathrm{l})\end{array}$ \\
\hline $\begin{array}{l}\text { Constant } \\
\text { outine } 1 \\
0830 \mathrm{~h} \text { ) }\end{array}$ & $4 \cdot 4 \pm 0 \cdot 2$ & $1 \cdot 3 \pm 0 \cdot 1$ & $0 \cdot 4 \pm 0 \cdot 1$ & $77 \pm 15$ & $34 \cdot 6 \pm 9 \cdot 4$ & $16 \cdot 1 \pm 2 \cdot 6$ \\
\hline $\begin{array}{l}\text { Constant } \\
\text { routine } 2 \\
(2230 \mathrm{~h})\end{array}$ & $4 \cdot 2 \pm 0 \cdot 1$ & $1 \cdot 2 \pm 0 \cdot 1$ & $0 \cdot 4 \pm 0 \cdot 1$ & $91 \pm 16$ & $19 \cdot 6 \pm 3 \cdot 8$ & $13 \cdot 4 \pm 2 \cdot 5$ \\
\hline
\end{tabular}




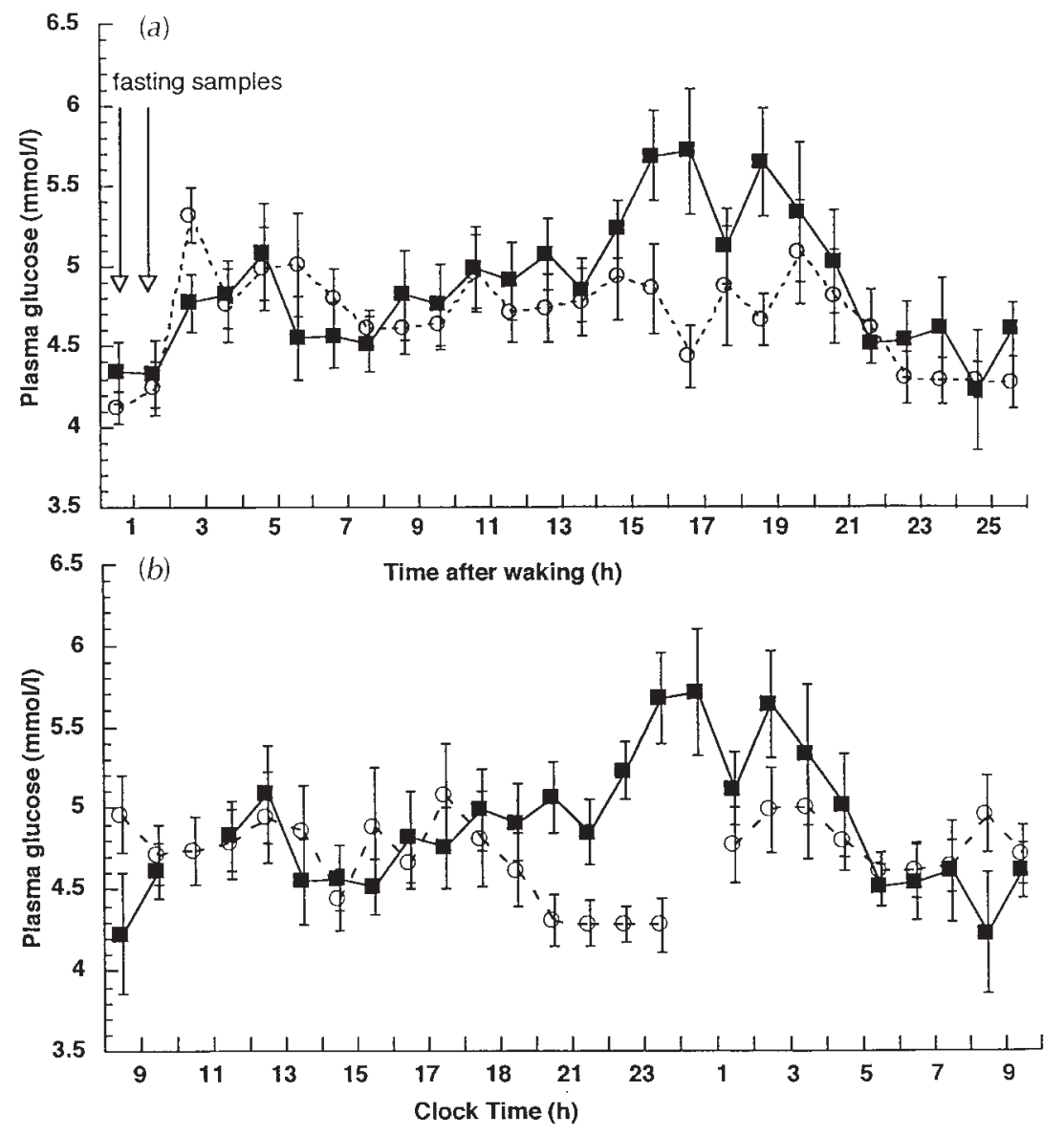

Figure 3 Plasma glucose concentrations in healthy volunteers during the two constant routines (a) plotted as a function of time after waking and (b) postprandial samples plotted as a function of clock time. Values are means \pm S.E.M., $n=7$. $\mathbf{\square}$, first constant routine;

$\bigcirc$, second constant routine.

routine 2 after living on a $27-\mathrm{h}$ day suggest that the major and minor peaks in the case of glucose and TAG have become more comparable, with a reduction in the major peak and an increase in the minor peak. This is also apparent when the data are plotted as a function of time after wake up.

Repeated measures analysis of variance with respect to time for each constant routine showed significant differences for TAG and glucose on the first constant routine $(P<0 \cdot 05)$ with a trend towards differences for insulin $(P=0 \cdot 09)$. Significant variation with respect to time was found for plasma TAG on the second constant routine $(P<0 \cdot 05)$. Subsequent differentiation of the $\mathrm{C}$ and $\mathrm{W}$ components as described above necessitated a complete set of samples from each subject; one further subject was eliminated from the analysis due to missing samples, leaving a total of 6 subjects. Subtraction of leg 1 from leg 2 as time after waking provided an estimate of $\mathrm{C}$.
Subsequent subtraction of the $\mathrm{C}$ component from the raw data expressed as real time provided an estimate of $\mathrm{W}$. The reliability of $\mathrm{C}$ and $\mathrm{W}$ was then assessed by repeated measures analysis of variance. The results are shown in Table 2. There was a significant effect of both the endogenous clock, C, and of the displaced sleep/wake cycle, W, for glucose and TAG but not for insulin.

Plasma NEFA levels were suppressed following feeding. They were, however, very variable and no significant differences in postprandial levels were found either with respect to time or between the two constant routines. Postprandial plasma GLP-1 data were also very variable and showed no consistent rise following feeding, or difference between the two constant routines. Plasma GIP levels rose following feeding. No significant differences in postprandial levels were found either with respect to time or between the two constant routines. These data are not shown and were not analysed further. 


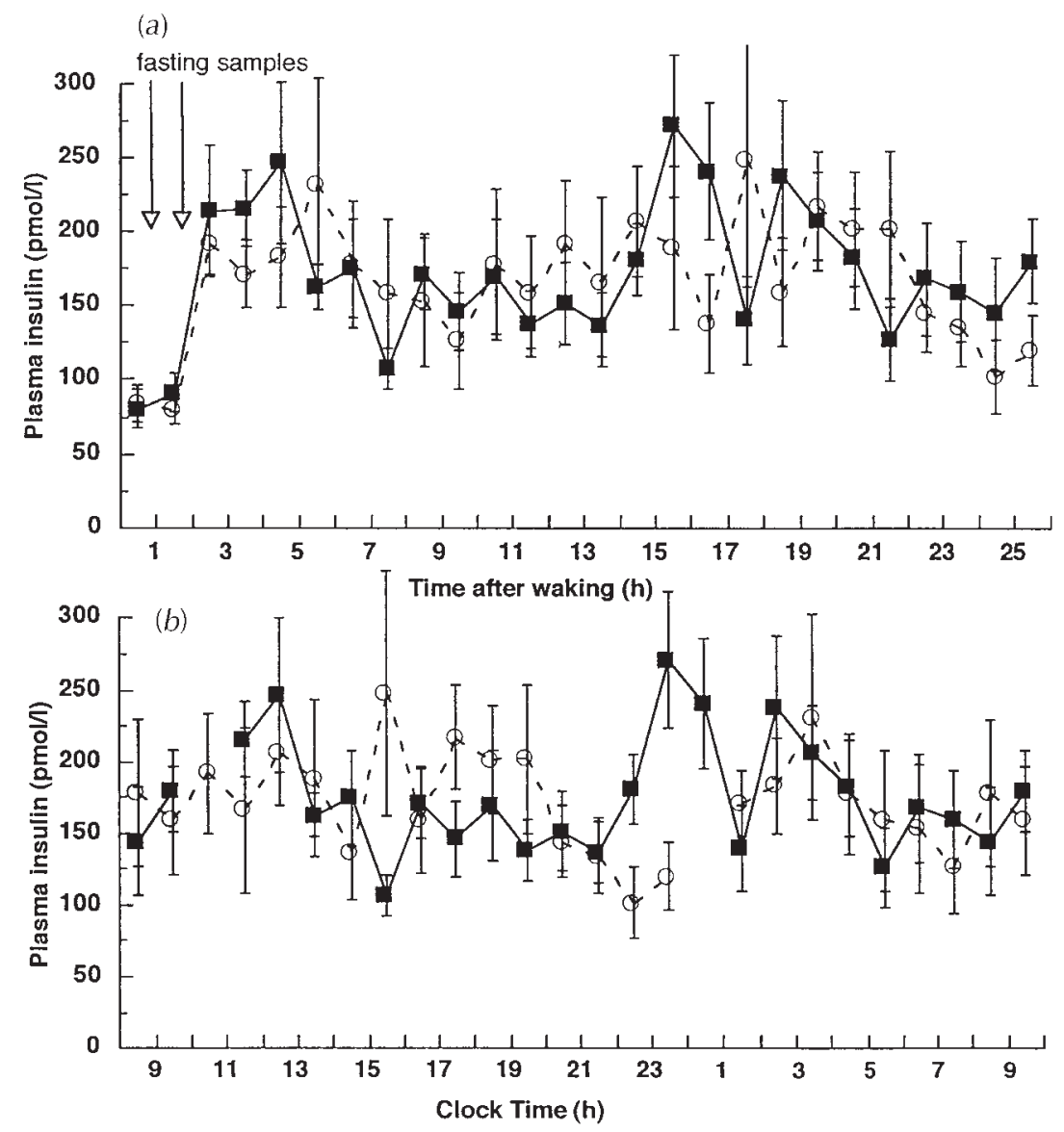

Figure 4 Plasma insulin concentrations in healthy volunteers during the two constant routines (a) plotted as a function of time after waking and (b) postprandial samples plotted as a function of clock time. Values are means \pm S.E.M., $n=7$. $\mathbf{\square}$, first constant routine;

$\bigcirc$, second constant routine.

\section{Discussion}

Melatonin is considered to be the best marker rhythm for the circadian clock (Arendt 1995). Individual melatonin profiles are highly reproducible and are less subject to masking factors than previously used marker rhythms such as core temperature and cortisol. The major masking factor for melatonin is sufficiently bright light with a minor effect of posture. If light and posture are controlled, salivary or plasma melatonin provides an accurate estimate of circadian phase position. The present data indicate that living on a 27-h day with access to all normal time cues does not shift the melatonin rhythm. The contribution of sleep timing in these circumstances is clearly negligible. As melatonin, and indeed core temperature, did not shift we can be certain that the endogenous clock was not affected by the imposed 27-h day and remained in the same phase position with respect to external clock time. During the first constant routine the contribution of the internal clock and of external factors such as time after wake up were presumed to be additive as subjects were in phase with the normal day. Similarly, during the second constant routine the contribution of the internal clock and external factors were presumed to be dissociated due to the displacement of the sleep-wake cycle, a situation commonly encountered by shift workers.

In the normal phase (the first constant routine) plasma glucose levels are significantly higher at night. This is in agreement with previous reports of impaired glucose tolerance following oral glucose (Aparicio et al. 1974), bolus or continuous intravenous glucose infusion (Van Cauter et al. 1989, Lee et al. 1992) or meals (Hampton 1983, Van Cauter et al. 1992) at night. These effects are due to a relative insulin resistance at night, causing decreased insulin-mediated peripheral glucose uptake, and are inversely correlated with the diurnal variation in circulating cortisol (Van Cauter et al. 1992). Dissociation of the internal clock and sleep in the second constant routine leads to a dampening of the peak response to glucose and the appearance of two comparable peaks, suggesting a 


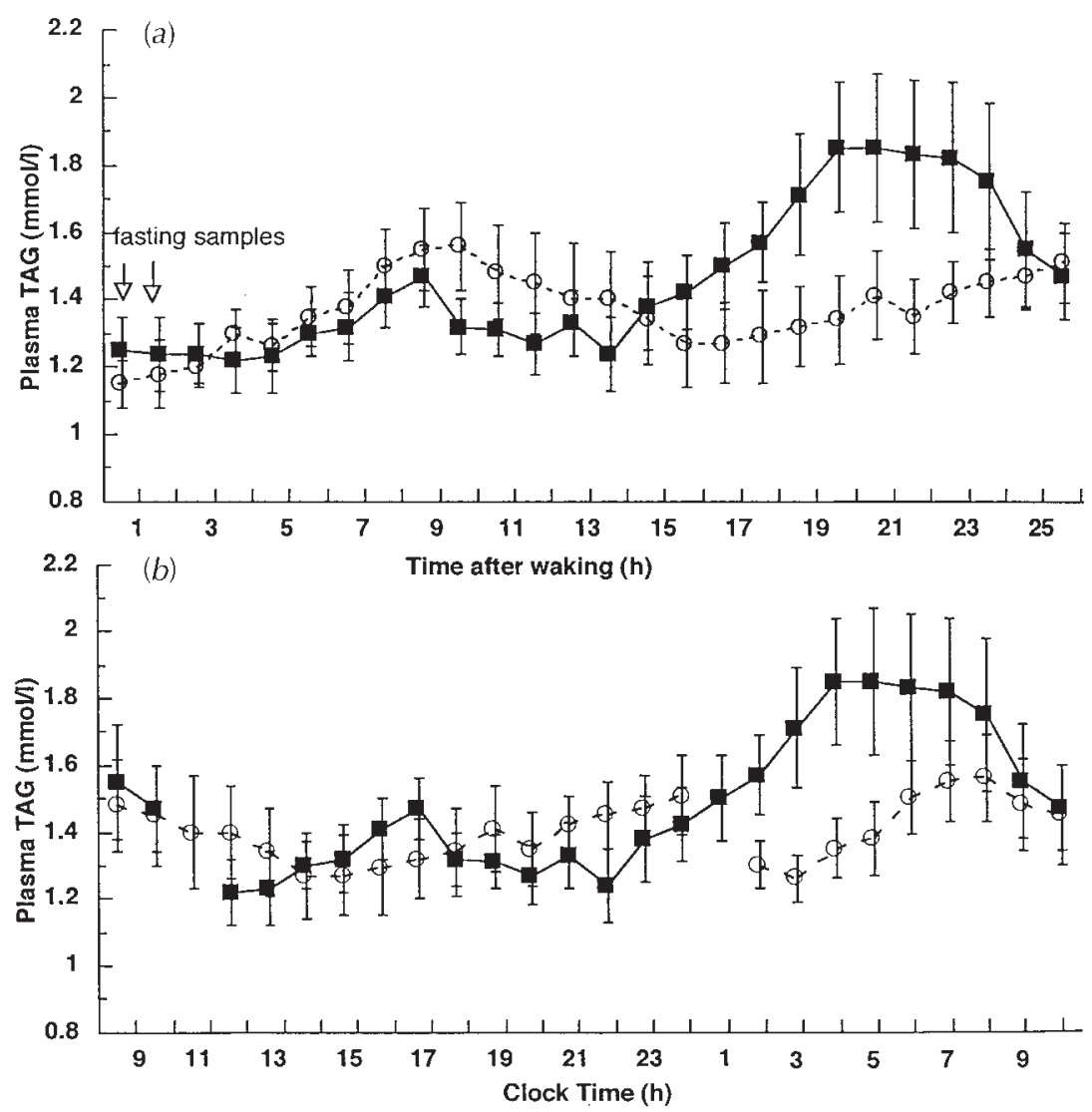

Figure 5 Plasma TAG concentrations in healthy volunteers during the two constant routines (a) plotted as a function of time after waking and (b) postprandial samples plotted as a function of clock time. Values are means \pm S.E.M., $n=7$. $\mathbf{\square}$, first constant routine;

$\bigcirc$, second constant routine.

'spreading' of glucose intolerance such that it occurs at two periods of the day. Sleep has been shown to increase circulating glucose levels following constant i.v. glucose infusion, due to decreased glucose utilisation, although diurnal variations in glucose have been shown to persist in the absence of sleep (Scheen et al. 1996). Diminished brain utilisation (which is insulin independent) has been shown in one study to account for approximately two thirds of

Table 2 Reliability of the endogenous circadian effects due to 'clock time' (the ' $\mathrm{C}$ ' component) and those due to length of prior wakefulness (the ' $W$ ' component) for circulating glucose, TAG and insulin. (See text for details)

\begin{tabular}{lll} 
& $\begin{array}{l}\text { C component } \\
\text { (probability of } \\
\text { significant effect) }\end{array}$ & $\begin{array}{l}\text { W component } \\
\text { (probability of } \\
\text { significant effect) }\end{array}$ \\
$\begin{array}{ll}\text { Glucose } \\
\text { Insulin }\end{array}$ & 0.036 & 0.040 \\
TAG & 0.099 & 0.055 \\
& 0.0074 & 0.046 \\
\hline
\end{tabular}

this effect; peripheral glucose utilisation accounted for the remainder (Boyle et al. 1994). The present study has shown for the first time that the length of wakefulness also has an effect on glucose tolerance, independent of any circadian rhythm or sleep itself.

Circulating insulin levels follow a similar pattern to the plasma glucose levels: they tended to be higher at night in the first constant routine but the differences did not achieve statistical significance. This is in agreement with previous workers who have found an inconsistent rise in plasma insulin levels at night, despite the raised plasma glucose levels (Shapiro et al. 1988, Van Cauter et al. 1992). This failure to observe a compensatory rise in plasma insulin in response to the raised glucose has been shown to be partially due to a diminished sensitivity of the pancreatic B cell to glucose (Lee et al. 1992) and also to an increase in the rate of insulin clearance from the plasma at night (Van Cauter et al. 1992). Measurement of insulin secretion rates using individual C-peptide kinetics (Van Cauter et al. 1992) would be of value in future work. 
The gastrointestinal peptides, GIP and GLP-1, stimulate insulin secretion via the enteroinsular axis (Morgan 1992). Their secretion rates are influenced both by the rate of gastric emptying and absorption of nutrients. Previous studies have shown a circadian rhythm in the gastric emptying rate of solid meals, with decreased emptying rates at night (Goo et al. 1987). The present study failed to demonstrate consistent differences in postprandial GIP and GLP-1 levels on either of the constant routines. This indicates that differences in gastric emptying and absorption rates are unlikely to affect carbohydrate and lipid tolerance in the present study, and that these gastrointestinal hormones are not responsible for the observed variations in circulating insulin.

This report details for the first time the striking increase of plasma TAG at night and its dissociation into two significant components related respectively to the internal clock and to time after wake up. There have been few studies of the diurnal variation in circulating lipid levels and the factors which might influence them. Diurnal changes in plasma TAG not under constant routine conditions have been shown (Romon et al. 1997); the magnitude of these changes correlates with fasting TAG levels (Fainaru et al. 1994). Expression of the alphasubtype hepatic peroxisome proliferator-activated receptor shows a diurnal rhythm which parallels corticosterone in the rat (Lemberger et al. 1996). This receptor indirectly influences TAG hydrolysis via regulation of apoprotein CIII synthesis and may, therefore, affect circulating TAG levels. A circadian rhythm of low density lipoprotein (LDL) receptor activity has been demonstrated which is influenced by cortisol, but not mediated by it (Balasubramaniam et al. 1994). Melatonin itself has been shown to inhibit LDL receptor activity and cholesterol synthesis in human mononuclear leucocytes (MüllerWieland et al. 1994); preliminary work in our laboratory (Chapman 1997) indicates that melatonin also influences lipoprotein lipase (LPL) activity, a key regulatory enzyme in circulating TAG clearance, in adipose tissue. LPL is activated by insulin; a lower nocturnal insulin sensitivity could, therefore, be associated with lower LPL activity and relatively impaired plasma TAG clearance. Insulin also suppresses very low density lipoprotein (VLDL) secretion by the liver (Sparks \& Sparks 1993); nocturnal insulin resistance could, therefore, also be associated with higher circulating TAG levels of hepatic origin.

Both insulin resistance and elevated circulating postprandial TAG concentrations are independent risk factors for cardiovascular disease (Reaven 1988, Sethi et al. 1993). There are several reasons why elevated postprandial TAG may confer increased cardiovascular disease risk. Chylomicron and VLDL remnant lipoproteins, derived from TAG-rich chylomicrons and VLDL, have been shown to be atherogenic, and raised plasma TAG predisposes towards the formation of small dense LDL, a lipoprotein subfraction whose elevation is also established as a risk factor for cardiovascular disease (Griffin et al. 1994). Our findings have important implications for shift workers, who may be eating at night during unadapted night shifts when a pattern of relative glucose and lipid intolerance is found. Shift workers have increased plasma TAG levels independent of energy and nutrient intake (Romon et al. 1992). They also have a higher risk of developing cardiovascular disease than day-time workers (Kawachi et al. 1996, Knutsson 1989). A growing part of the population in industrialised countries has irregular or displaced working hours, working during the early morning, late evening or night. The development of dietary or shift scheduling strategies and the timing of meals relative to sleep in order to minimise insulin insensitivity and postprandial lipid intolerance would, therefore, be desirable.

\section{Acknowledgements}

We would like to thank the MRC, the British Heart Foundation and Stockgrand Ltd for financial support of this study, and Drs Lara Blann and Ian McDonald for their assistance with the collection of blood samples on the constant routine study days.

\section{References}

Akerstedt T 1995 Adjustment of physiological circadian rhythms and the sleep-wake cycle to shift work. In Hours of Work: Temporal Factors in Work Scheduling, pp 185-198. Eds S Folkard \& TH Monk. New York: John Wiley.

Aparicio NJ, Puchula FE, Galiardino JJ, Ruiz M \& Llorens JM 1974 Circadian variation of the blood glucose, plasma insulin and human growth hormone levels in response to an oral glucose load in normal subjects. Diabetes 23 132-137.

Arendt J 1995 Melatonin and the Mammalian Pineal Gland, pp 66-109. London: Chapman and Hall.

Balasubramaniam S, Szanto A \& Roach PD 1994 Circadian rhythm in hepatic low-density-lipoprotein (LDL)-receptor expression and plasma LDL levels. Biochemical Journal 298 39-43.

Boyle PJ, Scott JC, Krentz RJ, Nagy E, Comstock E \& Hoffman C 1994 Diminished brain glucose metabolism is a significant determinant for falling rates of systemic glucose utilisation during sleep in normal humans. Journal of Clinical Investigation 93 529-535.

Carroll KF \& Nestel PJ 1973 Diurnal variation in glucose tolerance and insulin secretion in man. Diabetes 22 333-348.

Chapman C 1997 The effects of diet and gastrointestinal hormones on lipoprotein lipase activity and gene expression. PhD thesis, University of Surrey, Guildford, UK.

Czeisler CA, Johnson PJ, Duffy JF, Brown EN, Ronda JM \& Kronauer RE 1990 Exposure to bright light and darkness to treat physiologic maladaptation to night work. New England Journal of Medicine 322 1253-1259.

Elliott R, Morgan LM, Tredger JA, Deacon S, Wright J \& Marks V 1993 Glucagon-like peptide-1 (7-36) amide and glucose-dependent insulinotropic postprandial and 24-h secretion patterns. Journal of Endocrinology 138 159-166.

English J, Middleton B, Arendt J \& Wirz-Justice A 1993 Rapid direct measurement of melatonin in saliva using an iodinated tracer and solid phase second antibody. Annals of Clinical Biochemistry 30 415-416. 
Fainaru M, Schafer Z, Gavish D, Skurnik Y, Argov R \& Kaplan S 1994 Diurnal changes in plasma-lipoproteins of free-living healthy men consuming a standard diet. Israel Journal of Medical Science $\mathbf{3 0}$ 83-89.

Goo RH, Moore JG \& Greenberg E 1987 Circadian variation in gastric emptying of meals in humans. Gastroenterology 93 515-518.

Griffin BA, Freeman DJ, Tait GW, Thomson J, Caslake MJ, Packard CJ \& Shepherd J 1994 Role of plasma triglyceride in the regulation of low density lipoprotein (LDL) subfractions: relative contribution of small, dense LDL to coronary heart disease risk. Atherosclerosis $106241-253$.

Hampton SM 1983 The C peptide of proinsulin, its diagnostic use and a possible physiological role. PhD thesis, University of Surrey, Guildford, UK.

Hampton SM, Morgan LM, Lawrence N, Anastasiadou T, Norris F, Deacon S, Ribeiro D \& Arendt J 1996 Postprandial hormone and metabolic responses in simulated shift work. Journal of Endocrinology $151259-267$.

Kawachi I, Colditze G \& Stampfer MJ 1996 Heart disease in female shift workers. Shiftwork International Newsletter 1319.

Knutsson A 1989. Shift work and coronary heart disease. Scandinavian Journal of Sociology: Medical Supplement 44 1-36.

Lee A, Ader M, Bray GA \& Bergman R 1992 Diurnal variation in glucose tolerance. Cyclic suppression of insulin action and insulin secretion in normal weight but not obese subjects. Diabetes $\mathbf{4 1}$ $750-759$

Lemberger T, Saladin R, Vazquez M, Copoulos A \& Staels B 1996 Expression of the peroxisome proliferator-activated receptor-alpha gene is stimulated by stress and follows a diurnal rhythm. Journal of Biological Chemistry 271 1764-1769.

Minors D, Folkard S, MacDonald I, Owens D, Sytnik N, Tucker P \& Waterhouse J 1996 The difference in activity when in bed and out of bed. II Subjects on 27-hour 'days'. Chronobiology International 13 197-190.

Morgan LM 1992 Insulin secretion and the enteroinsular axis. In Nutrient Regulation of Insulin Secretion, pp 1-22. Ed P Flatt. London and Chapel Hill: Portland Press.

Morgan LM, Morris BA \& Marks V 1978 Radioimmunoassay of gastric inhibitory polypeptide. Annals of Clinical Biochemistry 15 172-177.

Müller-Wieland D, Behnke B, Koopman K \& Krone W 1994 Melatonin inhibits LPL receptor activity and cholesterol synthesis in freshly isolated human mononuclear leukocytes. Biochemistry and Biophysics Research Communications 203 416-421.

Owens DS, Macdonald I, Benton D, Sytnik N, Tucker P \& Folkard S 1996 A preliminary investigation into individual differences in the circadian variation of meal tolerance: effects on mood and hunger. Chronobiology International 13 435-447.

Reaven GM 1988 Role of insulin resistance in human disease. Diabetes 37 1595-1607.

Romon M, Nuttens M-C, Fievet C, Pot P, Bard JM, Turon D \& Fochart JC 1992 Increased triglyceride levels in shift workers. American Journal of Medicine 93 259-262.

Romon M, Le Fur C, Lebel P, Edme J-L, Fruchart J-C \& Dallongeville J 1997 Circadian variation of postprandial lipaemia. American Journal of Clinical Nutrition 65 934-940.

Scheen AJ, Byrne MM, Plat L, Leproult R \& Van Cauter E 1996 Relationships between sleep quality and glucose regulation in normal humans. American Journal of Physiology 34 E261-E270.

Service FJ, Hall LD, Westland RE, O'Brien PC, Go VL, Haymoud MW \& Rizza RA 1983 Effects of size, time of day, and sequence of meal ingestion on carbohydrate tolerance in normal subjects. Diabetologia 25 316-321.

Sethi S, Gibney M \& Williams C 1993 Postprandial lipid metabolism. Nutrition Research Reviews 6 161-183.

Shapiro ET, Tillel H, Polonsky KS, Fang VS, Rubenstein AH \& Van Cauter E 1988 Oscillation in insulin secretion during constant glucose infusion in normal man: relationship to changes in plasma glucose. Jornal of Clinical Endocrinology and Metabolism 67 307-314.

Sparks JD \& Sparks CE 1993 Hormonal regulation of lipoprotein assembly and secretion. Current Opinion in Lipidology 34 177-186.

Van Cauter E, Desir D, Decoster C, Fery F \& Balasse EO 1989 Nocturnal decrease in glucose tolerance during constant glucose infusion. Journal of Clinical Endocrinology and Metabolism 69 604-611.

Van Cauter E, Shapiro ET, Tillel H \& Polonsky KS 1992 Circadian modulation of insulin responses to meals: relationship to cortisol rhythm. American Journal of Physiology 262 E467-E475.

Received 21 October 1997
Accepted 2 February 1998 